\title{
Qualidade da água de rio na Amazônia: um estudo de caso sobre o rio Pará do Uruará
}

A contaminação da água pode ser vista como uma sequência de condições adversas que promove o crescimento e proliferação de agentes patogênicos. Com base nisso, este estudo buscou avaliar a qualidade da água do Rio Pará do Uruará, mensurando as características físico-químicas e microbiológicas. As amostras de água foram coletadas em quatro pontos do rio, usando sacos plásticos descartáveis e estéreis, próprios para coleta de água, devidamente identificados e acondicionados em ambiente térmico, para posterior análise em laboratório. Foram quantificados o $\mathrm{pH}$, dureza, turbidez, cor, condutividade, coliformes totais e Escherichia coli, seguindo a metodologia de ensaio de águas do Standard Methods for the Examination of Water and Wastewater (SMEWW). Nossos resultados mostraram que 0 $\mathrm{pH}$, dureza, turbidez, cor e condutividade estavam em conformidade com os valores máximos estabelecidos pela Resolução CONAMA $n^{\circ}$. $357 / 2005$, mas coliformes totais e Escherichia coli não atenderam aos padrões exigidos pela legislação ambiental vigente. A contaminação dos rios amazônicos rodeados por pequenas cidades tem ocorrido principalmente devido à ausência de saneamento básico, no qual a população descarta os efluentes domésticos diretamente no ecossistema aquático. Portanto, é necessário tornar público os resultados obtidos neste estudo, tendo em vista uma possível conscientização da população sobre os riscos à saúde que o consumo da água imprópria pode vir a causar. Além disso, possibilitar a realização de atividades de educação ambiental e em saúde voltadas à população, como forma de evitar a contaminação do rio.

Palavras-chave: Contaminação; Riscos à Saúde; Saneamento; Amazônia Brasileira.

\section{River water quality in the Amazon: a case study of the Pará do Uruará river}

\begin{abstract}
Water contamination can be seen as a sequence of adverse conditions that promote the growth and proliferation of pathogens. Based on this, this study sough to assess the water quality of the Pará do Uruará River, measuring the physicochemical and microbiological characteristics. The water samples were collected at four points along the river, using disposable and sterile plastic bags, suitable for water collection, properly identified and stored in a thermal environment, for subsequent analysis in the laboratory. The $\mathrm{pH}$, hardness, turbidity, color, conductivity, total coliforms and Escherichia coli were quantified, following the wate testing methodology of the Standard Methods for the Examination of Water and Wastewater (SMEWW). Our results showed that the pH, hardness, turbidity, color and conductivity were in compliance with the maximum values established by CONAMA Resolution no. 357/2005, but total coliforms and Escherichia coli did not meet the standards required by current environmental legislation. The contamination of Amazon rivers surrounded by small towns has occurred mainly due to the lack of basic sanitation, in which the population disposes of domestic effluents directly into the aquatic ecosystem. Therefore, it is necessary to make public the results obtained in this study, in view of a possible awareness of the population about the health risks that the consumption of inappropriate water can cause. In addition, enable the realization of environmental and health education activities aimed at the population, as a way to avoid river contamination.
\end{abstract}

Keywords: Contamination; Health Risks; Sanitation; Brazilian Amazon.

Topic: Desenvolvimento, Sustentabilidade e Meio Ambiente

Reviewed anonymously in the process of blind peer

Gustavo da Silva Flexa (1D)

Universidade Federal do Oeste do Pará, Brasil

http://lattes.cnpq.br/0813157010396923

http://orcid.org/0000-0002-0987-9889

gustavoflexa13@hotmail.com

Ana Paula Justino de Faria

Universidade Federal do Pará, Brasil

http://lattes.cnpq.br/6041546003155327

http://orcid.org/0000-0003-2729-5358

anafariaecol@gmail.com

Israel Nunes Henrique

Universidade Federal do Oeste do Pará, Brasi

http://lattes.cnpq.br/3418821931567495

http://orcid.org/0000-0003-2127-5428

israelnunes@yahoo.com.br

d

DOI: 10.6008/CBPC2179-6858.2021.007.0031
Received: 02/07/2021

Approved: 28/07/2021
Yane Santos Almeida

Universidade do Estado do Pará, Brasil

http://lattes.cnpq.br/4550855155546150

http://orcid.org/0000-0003-1095-4599

yanealmeida7@hotmail.com
Referencing this:

FLEXA, G. S.; FARIA, A. P. J.; HENRIQUE, I. N.; ALMEIDA, Y. S.. Qualidade da água de rio na Amazônia: um estudo de caso sobre o rio Pará do Uruará. Revista Ibero Americana de Ciências Ambientais, v.12, n.7, p.342-351, 2021. DOI: http://doi.org/10.6008/CBPC21796858.2021 .007 .0031 


\section{INTRODUÇÃO}

A Amazônia por muito tempo foi tratada como um gigante e infinito sistema homogêneo (LOUREIRO, 2012; BATISTA et al., 2019; SANTOS et al., 2020), composto por grande biodiversidade, na qual estavam inseridos elementos naturais como florestas, rios e riachos (PANTOJA et al., 2018; BRASIL et al., 2020). Contudo, a dimensão espacial desse bioma tem sido um atrativo para expansão de atividades antrópicas e econômicas na região, como por exemplo, a mineração, a exploração de madeira e os garimpos (SANTOS et al., 2010; GIATTI et al., 2012; MOURA et al., 2020).

Quando se fala em água na Amazônia há uma percepção errônea, na qual se confunde quantidade com qualidade da água disponível (TEIXEIRA et al., 2017), o que acaba mascarando os problemas relacionados à degradação dos rios e mananciais amazônicos. No entanto, a má qualidade da água tem se tornado um dos principais problemas e desafios para as famílias ribeirinhas, haja visto que a água para consumo é captada diretamente nos rios e riachos, e são consumidas sem que haja tratamento prévio (BECKER, 2005; SILVA et al., 2016; COSTA et al., 2020).

Os ribeirinhos são populações tradicionais que vivem em harmonia com a natureza, e principalmente com o ecossistema aquático, visto que habitam as margens desses ecossistemas (CASTRO et al., 2016; LIRA et al., 2016). No entanto, o crescimento populacional dessas comunidades de ribeirinhos vem transformando os modos de vida e a rotina de seus habitantes, visto que o crescimento desordenado às margens dos rios desencadeou o aumento no desmatamento da vegetação ripária, despejos domésticos em locais impróprios e construções habitacionais em áreas de risco (OLIVEIRA, 2016; SILVA et al., 2019; BÜHLER et al., 2020; RAMOS JÚNIOR et al., 2020).

O curso fluvial ainda é o mais utilizado como transporte, porém, isso não quer dizer que seja o mais econômico, já que de acordo com a localidade, e dependendo da época do ano, a viagem pode durar dias (CALEGARE et al., 2013). Para Rebouças (2004), o lixo e o esgoto despejados nos rios são um problema de elevada gravidade, já que em apenas um dia o rio corre vários quilômetros, e os dejetos que são levados pelas enxurradas chegam através do esgoto até os rios. Além disso, também são despejados por embarcações e pessoas que trafegam através de embarcações, tornando-o muitas vezes mais um depósito de dejetos, causando danos que podem ser irreversíveis para a natureza e, mais especificamente, para a qualidade da água (CASTRO, 2007; QUADROS et al., 2014; SILVA et al., 2019).

Devido às várias formas de utilização da água e à preocupação com a sua qualidade, o Conselho Nacional do Meio Ambiente (CONAMA) criou a Resolução no. 357/2005, que classifica os corpos hídricos em categorias de qualidade da água e seus respectivos usos. O Ministério da Saúde também estabeleceu, por meio da Portaria de Consolidação no. 5/2017, os indicadores de vigilância e controle da qualidade da água para o consumo humano. Essas legislações estabelecem valores máximos para parâmetros físicos, químicos e microbiológicos pois através dos resultados dessas análises é possível traçar estratégias de gestão e minimização dos impactos causados aos recursos hídricos (ABREU et al., 2015; CHAVES et al., 2020).

Neste contexto, visando investigar a qualidade das águas superficiais dos rios na Amazônia brasileira, 
este estudo teve como objetivo avaliar as possíveis alterações físico-químicas e microbiológicas da água do Rio Pará do Uruará, margeado pelo Distrito de Santa Maria do Uruará, no município de Prainha, Pará, Brasil.

\section{METODOLOGIA}

\section{Área de Estudo}

O Rio Pará do Uruará nasce a 60 km da sede do Distrito de Santa Maria do Uruará e desemboca no Rio Amazonas, nas proximidades da sede do município, permitindo um vasto espaço navegável que é utilizado por lanchas, canoas, barcos, balsas, botes, etc. Além disso, permite a utilização para várias atividades, como o embarque e desembarque de passageiros, transporte de mercadorias, madeiras e animais de grande porte, facilitando a vida dos comunitários com o seu vasto potencial hídrico (SANTOS, 2016).

Outro aspecto é a riqueza de vida aquática da região do Uruará, a qual abriga as mais variadas espécies de peixes e de outros crustáceos, como o camarão, que é muito consumido na região e contribui com a economia local (SANTOS, 2016). O Rio Pará do Uruará também serve como limite da Reserva Extrativista (RESEX) Renascer e o Distrito de Santa Maria do Uruará. Essa RESEX é caracterizada como uma unidade de Conservação Federal criada a partir do Decreto s/no de 05 de junho de 2009. A reserva tem uma área de 29.805,48 hectares, abrangendo mais de dez comunidades nas quais residem mais de 600 famílias.

O Distrito de Santa Maria do Uruará, como já mencionado anteriormente, é a maior comunidade ribeirinha às margens do Rio Pará do Uruará, possuindo aproximadamente oito mil habitantes em uma área urbana de aproximadamente 480ha (quatrocentos e oitenta hectares) definida através da Lei Municipal 99/2019. Devido a esse contingente populacional o local tem déficit quanto as questões de saneamento básico e deposição de resíduos.

\section{Coleta das Amostras}

As coletas foram realizadas em um perímetro de aproximadamente Três quilômetros de extensão no mês de maio de 2018 em quatro pontos às margens do Rio Pará do Uruará, sendo o Ponto A (-02 07' 56,97339" S; -53 38' 52,48640" W) à Jusante do Distrito de Santa Maria do Uruará, Pontos C (-02 $08^{\prime}$ $17,64447^{\prime \prime}$ S; -53 38' 08,34518" W) e D (-02 08' 16,25456" S; -53 38' 03,07134" W) em frente ao Distrito e Ponto B (-02 07' 52,36286" S; -53 37' 50,41795" W) à Montante do Distrito (Figura 1).

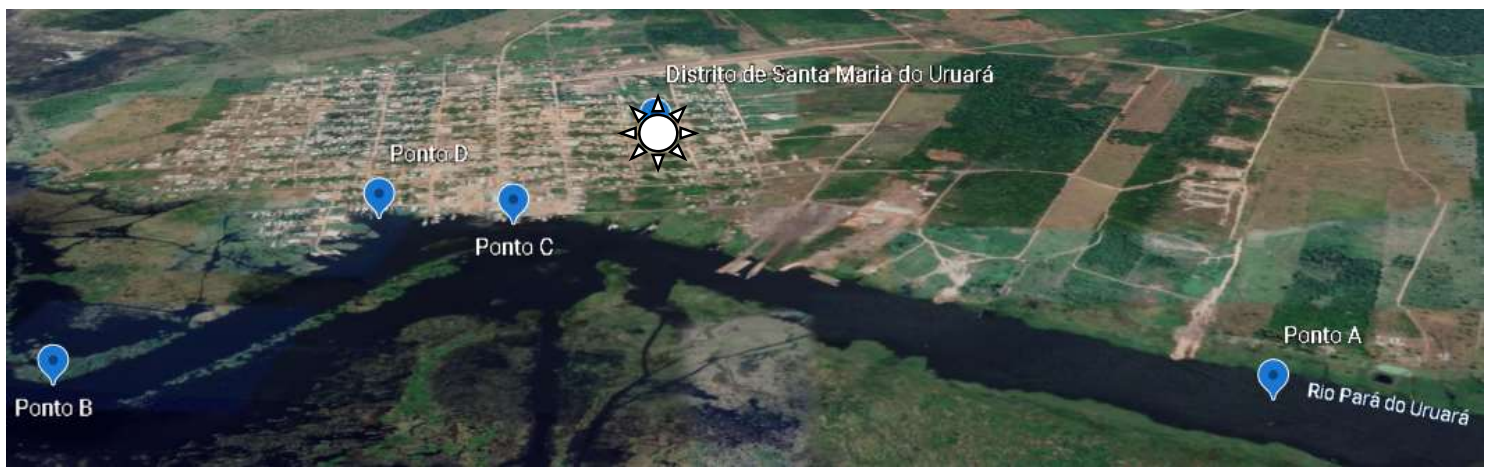

Figura 1: Distribuição espacial dos pontos de coleta de amostras de água no Rio Pará do Uruará. Fonte: Google Eart (2021) 
A coleta das amostras foi baseada no Guia Nacional de Coleta e Preservação de Amostras (CETESB, 2011). As amostras foram recolhidas contra a corrente e diretamente de águas superficiais, acomodadas em sacos plásticos descartáveis e estéreis de $120 \mathrm{ml}$, próprios para a realização de coleta de água, sendo devidamente identificados. Após as coletas, os mesmos foram acondicionados em ambiente térmico e transportados para Santarém, onde ocorreram as análises em laboratório (Figura 2).

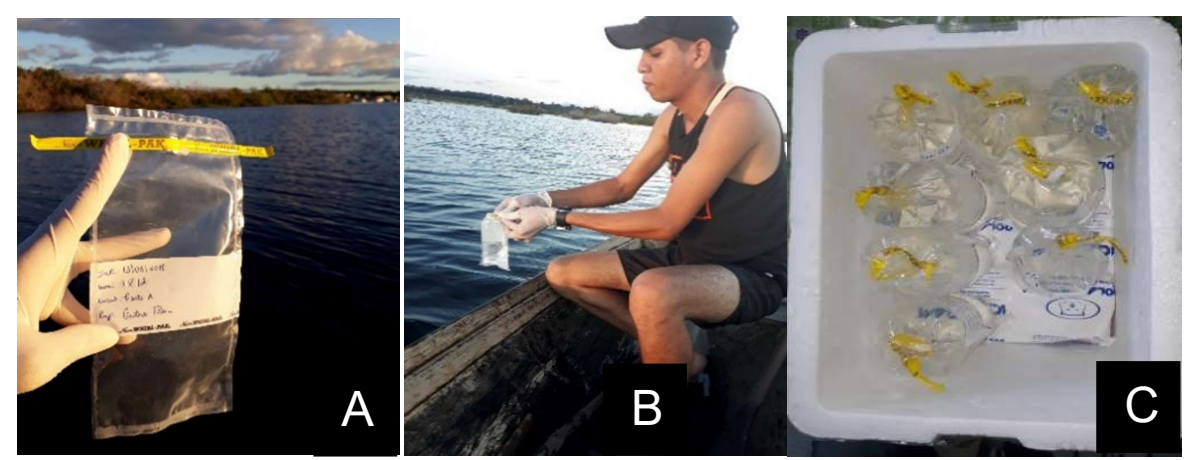

Figura 2: Coleta das Amostras.

A- Saca plástica descartável, estéril e própria para a coleta de amostras de água; B- realização da coleta de amostra de água em saco plástico estéril; C- amostras de água no ambiente térmico prontas para o transporte.

Para todas as amostras de água coletadas foram quantificados os valores de $\mathrm{pH}$, turbidez, dureza, condutividade, cor aparente, coliformes totais e Escherichia coli seguindo os métodos específicos para cada parâmetro descrito em Methods for the Examination of Water and Wastewater (SMEWW) (APHA et al., 2012) e resumidos na tabela 1.

Tabela 1: Metodologias e unidades adotadas para análise dos parâmetros físico-químicos e microbiológicos das amostras de água coletadas no Rio Pará Do Uruará, Pará, Brasil.

\begin{tabular}{lll}
\hline Parâmetro Analisado & Unidade de Medida & Metodologia \\
\hline Coliformes Totais & UFC $/ 100 \mathrm{~mL}$ & Método 9222 B e G \\
Escherichia coli & UFC $/ 100 \mathrm{~mL}$ & Método 9222 B e G \\
Ph & um. Ph & Método 4500 H B \\
Condutividade & uS.cml & Método 2510 B \\
Cor Aparente & UH & Método 2120 C \\
Dureza & NTU & Método 2320 B \\
Turbidez & UT & Método 2130 B \\
\hline
\end{tabular}

\section{RESULTADOS}

Os resultados obtidos para as amostras testadas nos quatro pontos do Rio Pará do Uruará, no Distrito de Santa Maria do Uruará - Prainha - Pará, quanto aos padrões físico-químicos e microbiológicos, estão representados na tabela 02 (abaixo), assim como também os valores máximos permitidos pela legislação vigente.

Tabela 2: Resultados dos Parâmetros Físico-Químicos e microbiológicos dos 4 pontos de coleta analisados no Rio Pará do Uruará.

\begin{tabular}{|c|c|c|c|c|c|}
\hline Parâmetro Analisado & V.M.P & Ponto A & Ponto B & Ponto C & Ponto D \\
\hline Coliformes Totais & Ausente & 289 & 239 & 210 & 200 \\
\hline Escherichia coli & Ausente & Ausente & Ausente & Ausente & Ausente \\
\hline $\mathrm{Ph}$ & $6,0-9,5$ & 6,59 & 6,28 & 6,88 & 6,69 \\
\hline Condutividade & 100 & 29 & 17 & 15 & 20 \\
\hline Cor Aparente & 75 & 16 & 18 & 29 & 33 \\
\hline Dureza & 500 & 18 & 21 & 21 & 24 \\
\hline Turbidez & 100 & 1,40 & 1,46 & 2,06 & 2,68 \\
\hline
\end{tabular}

*VMP: Valor Máximo Permitido. 
Não há uma classificação dos corpos hídricos na região feita pela Agência Nacional de Águas (ANA). No entanto, de acordo com os resultados dos parâmetros analisados no Rio Pará do Uruará, o mesmo pode ser enquadrado na Classe II da Classificação dos Corpos de Água da Resolução CONAMA no 357 (BRASIL, 2005).

\section{DISCUSSÃO}

A resolução 357/2005 da CONAMA propõe como normalidade até 1.000/100 ml para os parâmetros de coliformes totais, mas foi observado que os valores máximos para coliformes nas amostras coletadas nos quatro pontos variaram entre 200 e $289 \mathrm{ml}$ de coliformes, ou seja, a água do Rio Pará do Uruará está de acordo com a legislação vigente. Em contrapartida, a Portaria de consolidação no. 5/2017 define que a água para consumo humano deve estar ausente de coliformes totais. De acordo com esta Portaria, a água do Rio Pará do Uruará não pode ser consumida sem tratamento prévio, sendo necessárias medidas de desinfecção para poder torna-la própria para o consumo humano.

Esse resultado é importante ser divulgado para as comunidades ribeirinhas, pois as famílias ribeirinhas fazem captação de água para consumo humano direto do rio. E manter a qualidade da água no contexto amazônico é um desafio de forma geral, onde até mesmo as Unidades de Conservação encontram dificuldades quanto a potabilidade da água, como é o caso da FLONA do Purus e RESEX Verde Para Sempre. Isso acontece porque mesmo as áreas protegidas enfrentam problemas de qualidade da água similares aos encontrados nas demais áreas da Amazônia legal (GOMES et al., 2009; TEIXEIRA et al., 2017; SILVA et al., 2019). É imprescindível compreender que os determinantes socioeconômicos, em sua maioria, vão estar interligados à precária falta de saneamento básico (MARINHO et al., 2020).

Considerando a paisagem no entorno do Rio Pará do Uruará, principalmente associado a ocupação humana as margens do rio, era esperado que a água estivesse contaminada por Escherichia coli devido o lançamento direto de fluentes na água. A partir das análises conduzidas neste estudo, nós observamos que a ausência deste microrganismo na água. Sendo assim, encontra-se de acordo com os padrões estabelecidos pela Portaria de consolidação no. 5/2017 já que a mesma exige ausência de Escherichia coli para validar a qualidade e potabilidade da mesma.

Em todos os pontos da coleta a quantificação do pH foi de acordo com os padrões de qualidade de águas superficiais estabelecido na Resolução CONAMA no 357/2005, e os de potabilidade conforme a Portaria de consolidação no. 5/2017 do Ministério da Saúde, a qual recomenda que a água potável deve respeitar os padrões organolépticos e que o pH deve estar entre 6,0 a 9,5. Os valores de pH se encontravam entre 6,28 e 6,88, enquadrando-se nos padrões de classificação I, II e III de águas, quando comparado com a resolução 357 do CONAMA.

Ao comparar os resultados de $\mathrm{pH}$ desta pesquisa com os resultados de outras realizadas na região amazônica, como os de Batalha et al. (2014), que estudou as condições físico-químicas e biológicas em águas superficiais do Rio Tapajós, os de Alves et al. (2012), que estudou as condições do Rio Arari (Illha de Marajó, Pará), e dos de Aguiar et al. (2014), que realizou seu trabalho na região oeste do Pará, ambas tiveram valores 
de pH ácido. No entanto, os resultados da análise do Rio Pará do Uruará tiveram pH entre 6,28 e 6,88, com uma média de $\mathrm{pH}$ de 6,61, estando de acordo com os parâmetros para manutenção da vida aquática propostos na resolução 357/2005.

Aguiar et al. (2014), ao realizar outra pesquisa na região Oeste do Pará, mesma região onde fica o rio Pará do Uruará, obtiveram resultados de pH semelhantes, assim como também Mendes et al. (2016) ao avaliar o Rio Meia Ponte - GO, localizado em outra região do país, mas com características semelhantes. No entanto, ao avaliar o rio amazônico Juma, Pereira et al. (2013) constataram que no período de estiagem os valores de pH foram inferiores ao que é preconizado pela legislação $357 / 2005$, e que no período chuvoso os resultados ficaram próximos ao valor mínimo permitido pela legislação em questão, o que poderia ser uma justificativa para os resultados obtidos, já que o estudo foi realizado no período chuvoso.

A influência das mudanças climáticas na Amazônia afeta diretamente o modo de vida da população que reside na mesma (TOMÁZ et al., 2016). E as particularidades dos tipos de água da Amazônia não são levadas em consideração na CONAMA e Portaria de Consolidação.

Quanto à condutividade, em todas as quatro amostras de água em que foram realizados testes para tal parâmetro, foi identificado que os parâmetros estavam de acordo com os valores máximos permitidos estabelecidos pelo Ministério da Saúde, conforme a Portaria de consolidação no. 5/2017. Para o Ministério da Saúde (BRASIL, 2014), em águas naturais o valor geralmente apresenta teores de condutividade na faixa de 10 a $100 \mu \mathrm{S} / \mathrm{cm}$, enquanto que em águas contaminadas o valor máximo permitido que é de $1.000 \mu \mathrm{S} / \mathrm{cm}$. É importante que a água para consumo humano esteja dentro dos padrões permitidos de condutividade, pois confere à água a capacidade de transmitir a corrente elétrica, em função das muitas substâncias que podem estar presentes nela e se dissociando tanto em ânions como em cátions (ESTEVES, 2011; FRANÇA et al., 2019).

A média de condutividade foi 20,25 , mostrando que os valores deste parâmetro no Rio Pará do Uruará estavam dentro dos valores estabelecidos. Os resultados para o parâmetro condutividade corroboram com o estudo de Piratoba et al. (2017) que, ao caracterizar parâmetros de qualidade da água na área portuária de Barcarena - PA, constatou que os valores se encontravam dentro dos padrões, apesar de sofrer fortes interferências antrópicas.

O valor máximo permitido para cor, conforme a resolução 357/2005, é de até $75 \mathrm{mg} \mathrm{Pt/L}$, sendo assim, as quatro amostras de água analisadas se encontram dentro dos padrões exigidos pela legislação específica de classificação dos corpos hídricos. No entanto, a cor, assim como a turbidez, é considerada como parâmetro estético, ou seja, que pode levar à possível aceitação ou não do produto, dependendo se suas características são aceitáveis visualmente ou não. Assim, a cor indica a presença de possíveis substâncias dissolvidas na água, e o valor de referência utilizado como requisito para aceitação para que o liquido seja distribuído é de 15,0 U.C. (CETESB, 2018).

Se as amostras forem analisadas e comparadas com base nos requisitos para aceitação de como a água deve ser distribuída, que também é determinado pela portaria de consolidação no. 5/2017 do Ministério da Saúde, os quatro pontos analisados, quanto à determinação de cor aparente, teriam seus níveis alterados 
e não atenderiam aos padrões exigidos. Santos (2016) enfatiza que o embarque e transporte de madeiras em balsas acaba provocando muitos transtornos, sendo que os principais são a derrubada da mata ciliar ao longo do Rio Pará do Uruará, assim como da sua vegetação nativa, o que resultou na mudança de coloração da água e afugentou os comunitários de atividades de lazer no local, como a natação e o banho de rio que eram muito comuns, como também afastou várias espécies de peixes. Estes são dados que corroboram com os resultados obtidos por França et al. (2019).

O resultado das quatro amostras analisadas com relação à dureza da água, mostrou que ela se encontra nos padrões exigidos pela legislação vigente, a Portaria de consolidação no. 5/2017, que estabelece para dureza total o teor de $500 \mathrm{mg} / \mathrm{L}$ em termos de $\mathrm{CaCO} 3$ como o valor máximo permitido para água potável. De acordo com Brasil (2006), as águas que apresentam dureza $<50 \mathrm{mg} / \mathrm{L}$ de CaCO3 são consideradas como mole ou branda. Sendo assim, pode-se dizer que a água do rio Pará do Uruará, mais precisamente na vila de Santa Maria do Uruará, Prainha - Pará, é considerada como mole ou branda, devido ao fato de em todos os pontos em que foram feitas análises das amostras terem apresentado valor de dureza $<50 \mathrm{mg} / \mathrm{L} \mathrm{de} \mathrm{CaCO3}$. Os dados corroboram com Piratoba et al. (2017) que, ao analisarem um rio na Amazônia, o Rio Pará, também constataram que mesmo sofrendo bruscas influências antrópicas, o local podia ser caracterizado como de água mole ou branca.

Quanto à turbidez, em todos os pontos analisados as amostras enquadraram-se com os padrões de potabilidade estabelecidos pela legislação vigente, a Portaria de consolidação no 5/2017, que preconiza que as amostras não devem exceder 5,0 UT, pois, se superior a isso, passa a tratar a turbidez como um parâmetro sanitário, e para que isso seja visto com melhor eficiência, são estabelecidos parâmetros para que se possa mensurar valores para as diferentes situações. Os resultados de turbidez podem classificar as amostras para esse parâmetro como de classe I nos padrões exigidos pela resolução 357/2005, já que a mesma enfatiza o enquadramento nessa classificação em até 40 unidades nefelométrica de turbidez.

\section{CONCLUSÕES}

Esta pesquisa é parte de um projeto piloto que permitiu mensurar e quantificar parâmetros microbiológicos e físico-químicos da água em quatro pontos diferentes do rio Pará do Uruará. Além disso, ao comparar os dados obtidos com a literatura, os resultados demonstraram que a água do rio Pará do Uruará não se encontrava dentro dos padrões aceitáveis de potabilidade e, consequentemente, estava em condição imprópria para o consumo humano. Com isso, é necessário tornar público tais resultados, para que haja uma possível conscientização da população sobre os riscos à saúde que o consumo da água imprópria pode vir a causar, assim como também possibilitar a execução de atividades de educação ambiental e sanitária destinadas para a população, sendo este um meio para evitar a contaminação do rio.

De pose de resultados como os obtidos nessa pesquisa, espera-se se que órgãos e entidades voltados para o assunto, assim como o governo, tomem atitudes que possam minimizar a contaminação da água do Pará do Uruará por agentes patológicos, e que possam investir nos cuidados para com a saúde dos moradores, já que o desenvolvimento social e econômico de uma determinada região depende do 
atendimento das necessidades básicas da mesma.

A partir do conhecimento da realidade ambiental acerca da qualidade da água utilizada por uma comunidade, é possível formular diversas hipóteses e atividades que possam ser desenvolvidas. Além disso, alertar a população sobre a importância de formar cidadãos conscientes, afim de conservar esse bem comum e vital para a sobrevivência humana. Muitas outras questões ficam em aberto, mas, sobretudo, o desejo de que nossa presença nessas comunidades traga um diferencial e ajude para que continuemos promovendo uma responsabilidade ambiental e social em conjunto com eles, e que com isso tenham acesso a condições de vida mais digna e acessíveis.

\section{REFERÊNCIAS}

ABREU, C. H. M.; CUNHA, A. C.. Qualidade da Água em Ecossistemas Aquáticos Tropicais sob Impactos Ambientais do Baixo Rio Jari-AP: Revisão Descritiva. Biota Amazônia, v.5, n.2, p.119-131, 2015. DOI: http://dx.doi.org/10.18561/21795746/biotaamazonia.v5n2p119-131

AGUIAR, C. P. O.; PELEJA, J. R. P.; SOUSA, K. N. S.. Qualidade da água em microbacias hidrográficas com agricultura nos municípios de Santarém e Belterra, Pará. Rev. Árvore, Viçosa, v.38, n.6, p.983-992, 2014. DOI: http://doi.org/10.1590/S0100-67622014000600003

ALVES, I. C. C.; EL-ROBRINI, M.; SANTOS, M. L. S.; MONTEIRO, S. M.; BARBOSA, L. P. F.; GUIMARÃES, J. T. F.. Qualidade das águas superficiais e avaliação do estado trófico do Rio Arari (Ilha de Marajó, norte do Brasil). Acta Amaz., Manaus, v.42, n.1, p.115-124, 2012. DOI: http://dx.doi.org/10.1590/S0044$\underline{59672012000100014}$

APHA; AWWA; WEF. American Public Health Association; American Water Works Association; Water Environment Federation. Standard methods for the examination of water and wastewater. 22 ed. New York, 2012.

BATALHA, S. S. A.; MARTORANO, L. G.; BIASE, A. G.; MORALES, G. P.; PONTES, A. N.; SANTOS, L. S.. Condições físico-químicas e biológicas em águas superficiais do Rio Tapajós e a conservação de Floresta Nacional na Amazônia, Brasil. Rev. Ambient. Água, Taubaté, v.9, n.4, p.647-663, 2014. DOI: http://dx.doi.org/10.4136/ambi-agua.1304

BATISTA, I. M. S.; MIRANDA, L. M.. Os "Hidronegócios" nos rios da Amazônia. Rev. Bras. Hist., São Paulo, v.39, n.81, p.117-139, 2019. DOI: http://dx.doi.org/10.1590/180693472019v39n81-06

BECKER, B. K.. Geopolítica da Amazônia. Estud. Av., 2005, v.19, n.53, p.71-86. DOI: http://doi.org/10.1590/S0103$\underline{40142005000100005}$

BRASIL, L. S.; ANDRADE, A. I.; CALVÃO, L.; SILVA, K. D.. Aquatic insects and their environmental predictors: a scientometric study focused on environmental monitoring in lotic environmental. Environ Monit Assess, v.192, n.194, 2020. DOI: http://doi.org/10.1007/s10661-020-8147-z

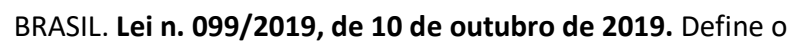
perímetro urbano do distrito de Santa Maria do Uruará e dá outras providências. Prefeitura Municipal de Prainha, 2019.

BRASIL. Ministério da Saúde. Fundação Nacional de Saúde. Manual de controle da qualidade da água para técnicos que trabalham em ETAS. Brasília: Funasa, 2014.

BRASIL. Ministério da Saúde. Portaria de Consolidação n. 5, de 28 de setembro de 2017. Dispõe consolidação das normas sobre as ações e os serviços de saúde do Sistema Único de Saúde. Brasília: DOU, 2018.

BRASIL. Ministério da Saúde. Secretaria de Vigilância em Saúde. Vigilância e controle da qualidade da água para consumo humano. Brasília: Ministério da Saúde, 2006.

BRASIL. Resolução n. 357, de 17 de março de 2005. Dispões sobre a classificação dos corpos de água e diretrizes ambientais para o seu enquadramento, bem como estabelece as condições e padrões de lançamento de efluentes, e dá outras providências. Brasília: DOU, 2005. p.58-63.

BÜHLER, B. F.; OLIVEIRA JUNIOR, E. S.; SOUZA, C. A.. Influência geológica e antrópica na qualidade da água de um córrego no Pantanal Norte, Brasil. Revista Ibero Americana de Ciências Ambientais, v.11, n.5, p.549-565, 2020. DOI: http://doi.org/10.6008/CBPC2179-6858.2020.005.0050

CALEGARE, M. G. A.; HIGUCHI, M. I. G.; FORSBERG, S. S.. Desafios metodológicos ao estudo de comunidades ribeirinhas amazônicas. Psicol. Soc., Belo Horizonte, v.25, n.3, p.571-580, 2013.

CASTRO, R. R. A.; OLIVEIRA, M. C. C.. Os termos "populações" e "comunidades" tradicionais e a apropriação dos conceitos no contexto amazônico. Mundo Amazónico, v.7, n.1-2, p.47-70, 2016. DOI:

http://doi.org/10.15446/ma.v7.55919

CETESB. Companhia Ambiental do Estado de São Paulo. Guia nacional de coleta e preservação de amostras: água, sedimento, comunidades aquáticas e efluentes líquidas. São Paulo: CETESB; Brasília: ANA, 2011.

CHAVES, H. S.; MORAIS, D. G.; DANTAS FILHO, H. A.; DANTAS, K. G. F.; BEIRAO, A. T. M.; SILVA, K. P.; SILVA, J. N.; SILVA, V. F. A.; SILVA, P. A.; CARVALHO, F. I. M.. Aplicação estatística multivariada para a avaliação físico-química na qualidade da água subterrânea na cidade de Parauapebas 
(Sudeste do Estado do Pará). Revista Ibero Americana de Ciências Ambientais, v.11, n.5, p.261-272, 2020. DOI: http://doi.org/10.6008/CBPC2179-6858.2020.005.0025

COSTA, K. A. D.; BENJAMIM, J. K. F.; AGUIAR NETO, S. A.; FERREIRA, T. M. C.; PHILIPPSEN, H. K.; ROSAS, J. C. F.; SERRA I. S. D.; SILVA, J. M. S.; LOPES, M. S. B.; SOUZA, C. M. N.. Avaliação da qualidade das Águas da Baia do Guajará para consumo humano. Revista Ibero Americana de Ciências Ambientais, v.11, n.6, p.150-159, 2020. DOI: http://doi.org/10.6008/CBPC2179-6858.2020.006.0014

ESTEVES, F.. Fundamentos de limnologia. 3 ed. Rio de Janeiro: Interciência, 2011.

FRANÇA, C. L. E.; ANJOS, F. S. C.; ANJOS, D. S. C.; SOUZA, L. S S.; SOUZA, R. S.; FINAZZI, G. A.; SILVA, A. M. C. Caracterização físicoquímica das águas superficiais do Rio São Francisco nos municípios de Juazeiro/BA e Petrolina/PE. Revista Ibero Americana de Ciências Ambientais, v.10, n.6, p.218-230, 2019. DOI: http://doi.org/10.6008/CBPC2179$\underline{6858.2019 .006 .0019}$

GIATTI, L. L.; CUTOLO, S. A.. Acesso à água para consumo humano e aspectos de saúde pública na Amazônia Legal. Ambient. Soc., v.15, n.1, p.93-109, 2012. DOI: http://doi.org/10.1590/S1414-753X2012000100007

GOMES, R. K. S.; PEREIRA, L. C. C.; RIBEIRO, C. M.; COSTA, R. M.. Dinâmica Socioambiental em uma Comunidade Pesqueira Amazônica, PA-Brasil. Revista de Gestão Costeira Integrada, v.9, n.2, p.101-111, 2009.

LIRA, T. M.; CHAVES, M. P. S. R.. Comunidades ribeirinhas na Amazônia: organização sociocultural e política. Interações, Campo Grande, v.17, n.1, p.66-76, 2016. DOI: http://dx.doi.org/10.20435/1518-70122016107

LOUREIRO, V. R.. A Amazônia no século 21: novas formas de desenvolvimento. Rev. direito GV, São Paulo, v.8, n.2, p.527552, 2012. DOI: http://doi.org/10.1590/S1808$\underline{24322012000200006}$

MARINHO, A. C. S. M.; PONTES, A. N.; BICHARA, C. N. C.. Environmental health and diarrhic diseases: socioeconomic, environmental and sanitary indicators in an amazonian municipality. Research, Society and Development, v.9, n.9, p.e659997803, 2020. DOI: http://doi.org/10.33448/rsd$\underline{\text { v9i9.7803 }}$

MENDES, T.; FAGUNDES, A.; PEREIRA, T.. Classificação Preliminar de Corpos d'água com Base na Resolução CONAMA no 357/2005: Caso do Rio Meia Ponte - GO. Ciência e Natura, v.38, n.3, p.1382-1393, 2016. DOI: http://doi.org/10.5902/2179460X21832

MOURA, L. S.; LOPES, R. B.; RIBEIRO, J. S.; FERNANDES, G. S. T.; ALMEIDA, R. M.; MELO, S. G.. A Influência da Sazonalidade sobre a qualidade de água para microbacia do Urumari, Santarém/Pará. Revista Ibero Americana de Ciências Ambientais, v.11, n.6, p.346-357, 2020. DOI: http://doi.org/10.6008/CBPC2179- 6858.2020.006.0028

OLIVEIRA, J. C.. Parâmetros Indicadores da Qualidade da Água no Município de Rorainópolis-RR. Ambiente: Gestão e Desenvolvimento, v.4, n.1, p.107-117, 2016. DOI: http://doi.org/10.24979/254
PANTOJA, A. P. P.; SOUZA, G. S.; NUNES, E. F. C.; PONTES, L. S.. Effect analysis of environmental factors on the children's Amazon community neuropsychomotor development. Journal of Human Growth and Development, p.232-239, 2018. DOI: http://dx.doi.org/10.7322/jhgd.152158

PEREIRA, A. R.; SANTOS, A. A.; SILVA, W. T. P.; FROZZI, J. C.; PEIXOTO, K. L. G.. Avaliação da qualidade da água superficial na área de influência de um lixão. Rev. Ambient. Água, Taubaté, v.8, n.3, p.239-2462013. DOI: http://dx.doi.org/10.4136/ambi-agua.1160

PIRATOBA, A. R. A.; RIBEIRO, H. M. C.; MORALES, G. P.; GONÇALVES, W. G.. Caracterização de parâmetros de qualidade da água na área portuária de Barcarena, PA, Brasil. Rev. Ambient. Água, Taubaté, v.12, n.3, p.435-456, 2017. DOI: http://dx.doi.org/10.4136/ambi-agua.1910

QUADROS, J. R.; COUTINHO, H. R. M.. Direito de águas na Amazônia e as futuras gerações. Constituição, Economia e Desenvolvimento: Revista da Academia Brasileira de Direito Constitucional, Curitiba, v.6, n.11, p.362-390, 2014. DOI: http://doi.org/10.24068/2177.8256.2014.6.11;362.390

RAMOS JÚNIOR, D. V.; FIGUEIREDO, E. S. A.; DORIA, C. R. C.; LIMA, M. A. L.; ROSSETE, A. N.; ATHAYDE, S. F.; MARQUES, E. E.; ARAÚJO, N. C.; BRASIL, W. B.. Os impactos das barragens hidrelétricas na pesca artesanal amazônica sob o olhar dos sistemas socioecológicos. Revista Ibero Americana de Ciências Ambientais, v.11, n.6, p.209-223, 2020. DOI: http://doi.org/10.6008/CBPC2179-6858.2020.006.0018

REBOUÇAS, A. C.. Uso Inteligente da Água. São Paulo: Escrituras, 2004

SANTOS, L. F.; MARINHO, E. R.; MOREIRA, F. S. A.; CARNEIRO, B. S.; FAIAL, K. C. F.. Avaliação da qualidade da água da baía do Guajará em Belém/PA. Revista Ibero Americana de Ciências Ambientais, v.11, n.2, p.367-380, 2020. DOI: http://doi.org/10.6008/CBPC2179$\underline{6858.2020 .002 .0034}$

SANTOS, A. R.; TREIN, E. S.. A educação ambiental no contexto ribeirinho Amazônico. Revista de Estudos Universitários, v.36, n.3, 2010.

SANTOS, S. P.. Relatório acerca do Estudo socioeconômico da região do Uruará, Prainha - PA, 2015-2016. Santa Maria do Uruará - Síntese/Relatório do mini-estudo sócio econômico da Vila De Santa Maria do Uruará do Região do Uruará - 2015 - 2016. 2016.

SILVA, A. L. A.; ROCHA, G. M.. Cidade e água: a produção do espaço na Bacia do Igarapé do Tucunduba em Belém-PA. Revista Brasileira de Desenvolvimento Regional, Blumenau, v.7, n.1, p.91-114, 2019

SILVA, C. P.; VARGAS, R. R.; ARRUDA, R. O. M.; ROSINI, E. F.. Efeitos do uso e ocupação da terra na qualidade da água da sub-bacia hidrográfica Cabosol, Guarulhos/SP. Revista Ibero Americana de Ciências Ambientais, v.10, n.6, p.260-273, 2019. DOI: http://doi.org/10.6008/CBPC21796858.2019 .006 .0023

SILVA, S. H.; NODA, S. N.. A Dinâmica entre as águas e terras na Amazônia e seus efeitos sobre as várzeas. Rev. Ambient. 
Água, Taubaté, v.11, n.2, p.377-386, 2016. DOI: http://dx.doi.org/10.4136/ambi-agua.1805

TEIXEIRA, T. H.; FERREIRA NETO, J. A.; APARECIDA, R. M.; ARAGÃO, N. F.. As Unidades de Conservação de Uso Sustentável no Bioma Amazônico: Dilemas e Perspectivas Para o Desenvolvimento Sustentável. Revista Portuguesa de
Estudos Regionais, n.46, p.71-89, 2017.

TOMÁZ, A. F.; SANTOS, G.. Conflitos Socioambientais e Violações de Direitos Humanos em Comunidades Tradicionais Pesqueiras no Brasil. - Brasília: Conselho Pastoral Dos Pescadores, 2016.

A CBPC - Companhia Brasileira de Produção Científica (CNPJ: 11.221.422/0001-03) detém os direitos materiais desta publicação. Os direitos referem-se à publicação do trabalho em qualquer parte do mundo, incluindo os direitos às renovações, expansões e disseminações da contribuição, bem como outros direitos subsidiários. Todos os trabalhos publicados eletronicamente poderão posteriormente ser publicados em coletâneas impressas sob coordenação da Sustenere Publishing, da Companhia Brasileira de Produção Científica e seus parceiros autorizados. Os (as) autores (as) preservam os direitos autorais, mas não têm permissão para a publicação da contribuição em outro meio, impresso ou digital, em português ou em tradução. 